\title{
Gömülü Ikinci Molar Sıklığı: Retrospektif Çalışma
}

\author{
M. Fatih Şentürk(0000-0001-8611-281X) ${ }^{\alpha}$, Özlem Görmez(0000-0001-9516-6625), \\ Sinem Sırlı Yılmaztürk(0000-0001-7375-4004) ${ }^{\beta}$
}

Selcuk Dent J, 2021; 8: 763-767 (Doi: 10.15311/selcukdentj. 822798)

Bașvuru Tarihi: 10 Kasım 2020 Yayına Kabul Tarihi: 05 Ocak 2021

öz

\section{Gömülü İkinci Molar Sıklığı: Retrospektif Çalışma}

Amaç: Türk toplumunun alt grubunda gözlenen ikinci molar dişlerin gömülü kalma sıklığını araştırmaktır.

Gereç ve Yöntemler: 2018 Ocak-Haziran ayları arasında Süleyman Demirel Üniversitesi Ağız, Diş ve Çene Radyolojisi bölümünde çeşitli sebeplerle panoramik radyograf (PR) alınmış hastaların PR'leri gömük ikinci molar diş açısından geriye dönük incelendi. Hastaların demografik verileri (yaş, cinsiyet, sendrom varlığı), gömük ikinci molar dişlerinin varlığı, sayıları, konumları, pozisyonları, tek ya da çift taraflı oluşu, tedavi şekli ve komşu 3.molar diş durumu açısından değerlendirildi.

Bulgular: 12113 hastaya ait PR'lerin incelenmesi sonucunda 16 hastada 21 gömük ikinci molar tespit edildi ve sıklık \% 0,13 olarak bulundu. Gömük ikinci molar dişlerin büyük çoğunluğu alt çenede (\% 61.90), tek taraflı (\% 87.50) ve vertikal pozisyonda (\% 38.10) gözlendi. Bu dişlerle ilişkili 3.molarların genellikle gömülü (\% 87.50) olduğu bulundu. Asemptomatik olan gömülü dişlerin genellikle takibi (\% 85.71) tercih edildi.

Sonuç: İkinci molar dişlerin gömülü kalması çok nadir görülen bir durumdur. Bu dişler kaynaklı oluşabilecek semptomların önüne geçebilmek adına PR' lerin detaylı bir şekilde incelenmesi ve hastaların takibi önem arz etmektedir.

\section{ANAHTAR KELIMELER}

Gömülü, İkinci molar, Sıklık, Panoramik radyograf

Gömülü diş, erüpsiyon yolunda bulunan fiziksel bir engel sebebiyle ya da sebep olmaksızın, sürme zamanı gelmiş olmasına rağmen üzerindeki kemik veya yumuşak doku tarafından oklüzyona gelmesi engellenmiş ve hâlen sürememiş olan dişler için kullanılan bir terimdir. ${ }^{1,2}$ Ağızda gömülü kalma oranı en yüksek olan dişler üçüncü molar dişlerdir. Maksiller kanin ve mandibular ikinci premolar dişler ise gömülü kalma sıklığı sıralamasında üçüncü molar dișleri takip etmektedir. ${ }^{3,4}$ Daimi ikinci molar dișlerin gömülü kalma durumu çok nadir olup genellikle tek taraflı ve mandibular arkta daha sık görülmektedir. ${ }^{4-6}$ Etiyolojisi tam olarak bilinmemekle birlikte genetik ve sistemik faktörlerle beraber yetersiz ark uzunluğu, persiste süt dişleri, enfeksiyon, anormal pozisyonlu komşu üçüncü molar dişler, süpernümerer dişler, ikinci premolar dişlerin geç sürmesi, kist- tümör benzeri patolojik oluşumlar gibi lokal faktörlerin ikinci molar dişlerin gömülü kalmasında etkin

\section{ABSTRACT}

Retrospective Analysis of Impacted Second Molars Frequency

Background: To evaluate the frequency of second molar teeth in permanent dentition of the sub population of Turkish population.

Methods: The panoramic radiograph (PR) of patients who received a PR for various reasons at the Süleyman Demirel University Oral and Maxillofacial Radiology Department between January and June 2018 were retrospectively examined in terms of impacted second molar teeth. Patients demographic data (age, gender, presence of the syndrome), the presence of impacted second molar teeth, their number, location, position, unilateral or bilateral status, type of treatment, and condition of the adjacent 3rd molar teeth were evaluated.

Results: PR of 12113 patients were examined and 21 impacted second molars were detected in 16 patients $(0.13 \%)$. The majority of impacted second molars were observed in mandible (\% 61.90) and seen unilaterally (\% 87.50) and vertically (\% 38.10). It was found that the 3rd molars associated with these teeth were often impacted $(\% 87.50)$. Asymptomatic impacted teeth were generally followed up (\% 85.71).

Conclusion: Second molar impaction is a rare entity. In order to prevent the symptoms that may arise from these teeth, detailed PR examination and patient follow up is important.

\section{KEYWORDS}

Impacted, Second molar, Frequency, Panoramic, Radiography

olabileceğinden bahsedilmiştir. ${ }^{6-11}$

Gömülü dişlerin teşhis ve tedavi yöntemlerinin belirlenebilmesi ile komplikasyonların en aza indirilebilmesi için klinik muayene ile birlikte detaylı bir radyolojik incelemenin yapılması şartır. Diş hekimliği pratiğinde birçok oral ve maksillofasiyal hastalığın tanı ve tedavi planlamasında $P R$, düşük radyasyon dozu ile geniş anatomik alanları göstermesi, çok kısa sürede çekim yapılmasına olanak sağlaması, hastanın işleme olan toleransının yüksek olması gibi avantajları nedeniyle rutin olarak kullanılır. ${ }^{12}$ Gömülü ikinci molar dişlerin teşhisinde PR önemli bir rol oynar. Gömülü dişlerin bitişik dişler ve komşu anatomik yapılarla olan ilişkisinin detaylı incelenebilmesi için iki boyutlu PR yerine, üç boyutlu görüntüleme sağlayan konik ışınlı bilgisayarlı tomografiden (KIBT) yararlanılabilir. ${ }^{12}$

Gömülü dişler hiçbir patolojiye neden olmadan,

\footnotetext{
${ }^{\alpha}$ Ankara Yıldırım Beyazıt Üniversitesi Diş Hekimliği Fakültesi Ağız, Diş ve Çene Cerrahisi AD, Ankara, Türkiye

${ }^{\beta}$ Süleyman Demirel Üniversitesi Diş Hekimliği Fakültesi Ağız Diş ve Çene Radyolojisi AD, Isparta, Türkiye
} 
asemptomatik olarak yıllarca çenelerde kalabildikleri gibi ağrı, perikoronitis, trismus, enfeksiyon, temporomandibular eklem problemleri, komşu dişlerde kök rezorpsiyonu, kist veya tümör oluşumu gibi durumlara neden olabilirler. ${ }^{13}$ Tedavide, asemptomatik olan dişler için takip, ortodontik tedavi gibi seçenekler mevcutken, semptom gösterenlerde çekim kaçınılmaz olabilmektedir. ${ }^{6,11}$

Üçüncü molar dişlerin gömülü kalma sıklığı ile ilgili literatürde çok sayıda çalışma mevcutken daha az gömülü kalan ikinci molar ve diğer daimi dişlerin gömülü kalma sıklığıyla ilgili çalışma sayısı oldukça azdır. Bu çalışmanın amacı; gömülü ikinci molar dişlerin sıklığının yaş, cinsiyet, tek ya da çift taraflı olma durumu, pozisyon, konum, komşu 3.molar dişin durumu gibi verilerle desteklenmesi ile tedavi alternatiflerinin gözden geçirilmesidir.

\section{GEREÇ VE YÖNTEMLER}

$\mathrm{Bu}$ retrospektif çalışma için Süleyman Demirel Üniversitesi Tıp Fakültesi Klinik Araştırmalar Etik Kurulu'ndan gereken onay alındı (TarihSayı:02.04.2020-96). Ocak-Haziran 2018 yılları arasında farklı sebeplerle Süleyman Demirel Üniversitesi Diş Hekimliği Fakültesi Ağız, Diş ve Çene Radyolojisi Kliniği'ne başvuran, 18 yaş ve üstü hastalardan çeşitli nedenlerle elde edilen 12113 PR geriye dönük olarak tarandı.

Panoramik radyograflar, Planmeca Promax (Helsinki, Finlandiya, ışınlama parametreleri 66-68 kVp, 7-13 mA, $16 \mathrm{sn})$ dijital panoramik cihazı ile elde edildi ve görüntüler karanlık odada bir araştırmacı tarafından değerlendirildi. Hastalara ait yaş, cinsiyet, sistemik hastalık bilgileri ve bu hastalarda uygulanan tedavi yöntemleri, gömük ikinci molar dişlerin sayısı, lokasyonu, pozisyonu, tek ya da çift taraflı olmaları, ilişkili olduğu patolojiler ve komşu üçüncü molarların görüntü arşivleme ve iletişim siteminden (PACS) incelendi ve kayıt altına alındı. Radyograflarda oklüzal düzleme çekilen hattan bir kısmı veya tamamı alt çenede aşağıda, üst çenede yukarıda olan dişler gömük olarak kabul edildi.

Literatürde üçüncü molarların pozisyonlarının değerlendirmesinde kullanımından bahsedilen derinlik ve açı sınıflandırmaları ikinci molarlara uyarlanarak kullanıldı ve ölçümler Planmeca Romexis 3.8.3 (Helsinki, Finlandiya) programında yapıldı. Dişin derinliği Class A (yüksek okluzal seviye): Molar dişin en üst kısmı okluzal düzlemle aynı seviyede; Class B (Orta okluzal seviye): Molar dişin en üst kısmı komşu dişlerin mine-sement sınırıyla okluzal düzlem arasında; Class C (Derin okluzal seviye): Molar dişin en üst kısmı komşu dişlerin mine-sement sınırının apikalinde olarak Pell ve Gregory* sınıflamasındaki gibi sınıflandırıldı. Açısal pozisyon ise gömük ikinci molar ile komşuluğundaki birinci molar dişin oklüzal yüzeyinin görünen en üst noktasından çizilen teğetler arasındaki açı hesaplanarak $0-10^{\circ}$ arası ise vertikal $(\mathrm{V}) ; 11^{\circ}-70^{\circ}$ arası ise mezioanguler (MA) veya distoanguler (DA); $\geq 71^{\circ}$ ise horizontal $(\mathrm{H})$ olarak Shiller15 sınıflamasına göre sınıflandırıldı.

\section{BULGULAR}

Geriye dönük olarak yapılan taramada 6399 kadın hastanın \% 0.11 inde $(n=7), 5714$ erkek hastanın ise \% 0.16 sında $(n=9)$ gömük 2. molar diş tespit edildi. 16 hastanın \% 43.75 ini oluşturan kadın hastalar 20-29 yaş aralığında değişmekte olup ortalama yaşları 22.57 iken \% 56.25 ini oluşturan erkek hastalar 20-28 yaş aralığında olup ortalama yaşları 22.78 olarak bulundu. 16 hastada 2 tek taraflı (\% 12.5), 14 çift taraflı (\% 87.5) olarak tespit edilen 21 gömük 2. molar dişin 8'i (\% 38.10) üst çenede (5 sağ-3 sol) izlenirken, 13'ü (\% 61.90) alt çenede (7 sağ6 sol) izlendi.

Derinlik açısından yapılan değerlendirmede 21 adet gömük 2.molar dişin 1'i (\% 4.76) Sınıf A, 10'u (\% 47.61) Sınıf B ve geriye kalan 10'u (\% 47.61) ise Sınıf C olarak tespit edildi. Açı ölçümüne bağlı olarak dişin pozisyonun belirlendiği sınıflama açısından ise gömülü ikinci molar dişler en fazla vertikal pozisyonda görüldü $(n=8, \%$ 38.10). Geriye kalan dişlerin 4'ü (\% 19.04) horizontal, 4'ü (\% 19.04) MA ve 5'i (\% 23.81) DA pozisyonda tespit edildi.

Gömülü ikinci molar dişlerin etrafında kist-tümör benzeri herhangi bir patolojik oluşumun izlenmediği çalışmamızda 21 adet gömük 2. molar dişle beraber olan 16 adet 3. molar dişlerin 2'si (\% 12.5) sürmüş, 14' ü (\% 87.5) gömülü olarak tespit edilmiştir. Bütün hastaların non-sendromik olduğu çalışmamızda asemptomatik 18 dişin takibi (\% 85.71) uygun görülürken 1 (\% 4.76) diş ortodontik tedavi yardımıyla sürdürülmüş, geriye kalan 2 (\%. 9.52) diş ise cerrahi olarak çekilmiştir. Cerrahi çekim esnasında yandaki dişlere ve anatomik yapılara zarar vermemek adına mimal travma ile çalışılmıştır (Resim $1,2,3)$.

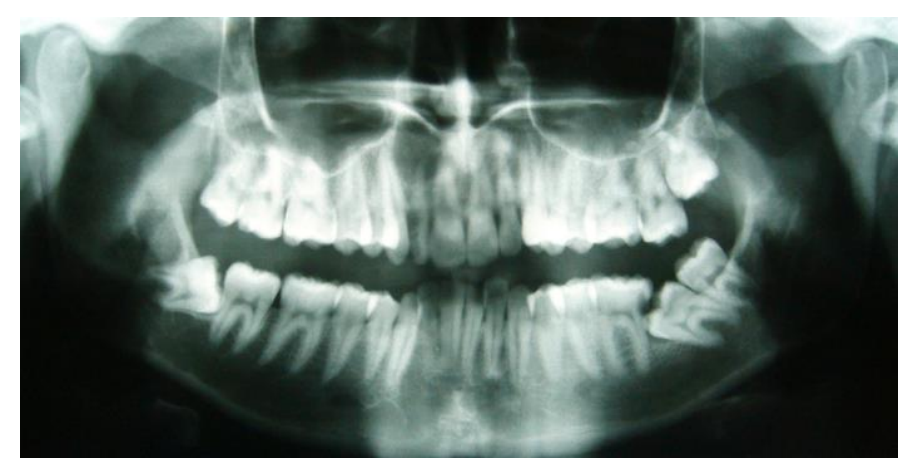

Resim 1

Gömük ikinci molar dişin radyografik görünümü 


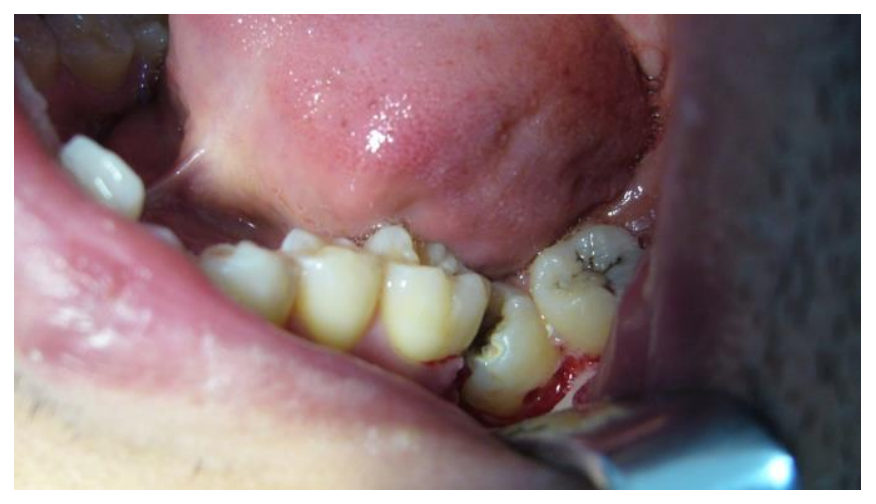

Resim 2

Gömük ikinci molar dişin klinik görünümü

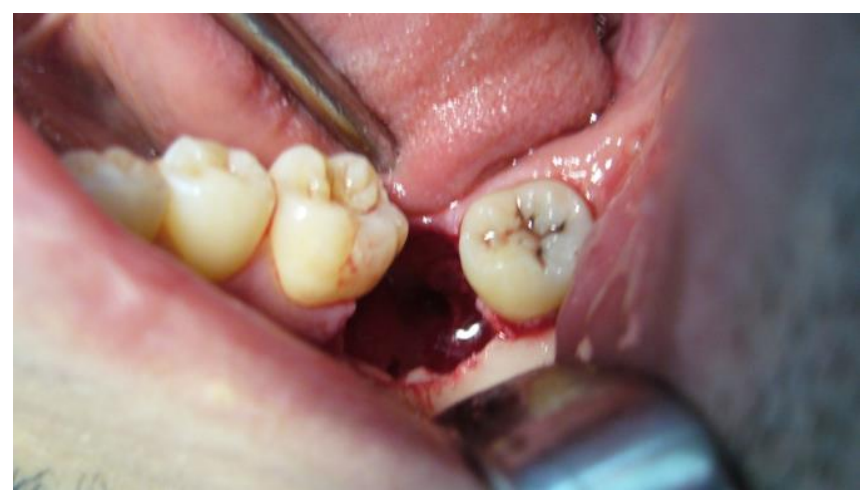

Resim 3

Komşu dişlere zarar vermeden çekimi yapılmış gömük ikinci molar diş çekim soketi

\section{TARTIŞMA}

İkinci molar dişlerin gömülü kalması oldukça nadir görülen bir durum olup görülme sıklığı \% 0.03- \% 1.36 arasında değişmektedir. ${ }^{6,16}$ Genç yaş grupları ve ortodontik hasta grupları üzerinde geçekleşen çalışmalarda bu oranların daha yüksek olabileceği belirtilmiştir. ${ }^{10,16}$ Farklı popülasyonlar üzerinde yapılan spesifik çalışmalarda Srinivasan ve ark.10 gömük ikinci molar görülme sıklığını Güney Hint popülasyonu üzerinde $\% 0.16$, Şimşek Kaya ve ark. ${ }^{6}$ gömük ikinci molar görülme sıklığını Türk popülasyonu üzerinde \% 0.12 , Bereket ve ark. 11 ise $\% 0.16$ olarak bildirmişlerdir. Bizim çalışmamızda da 12113 hastanın 16' sında (yaş ortalaması: 22.68) gömük ikinci molar tespit edilmiş olup oran \% 0.13 olarak bulunmuş ve diğer çalışmalarla uyumlu sonuç vermiştir.

Gömülü ikinci molarların etiyolojisi kesin olarak kanıtlanmamış olsa da ektopik veya malpoze üçüncü molarlar ve ilişkili patolojiler rol oynayabilmektedir. ${ }^{8,9,17}$ Mandibular üçüncü ve ikinci molarların aynı anda gömülü olması ender görülen bir durumdur. ${ }^{18}$ Şimşek Kaya ve ark. ${ }^{6} 15$ hasta üzerinde gerçekleştirdikleri çalışmalarında 25 ikinci molar dişin \% 84'ünün komşu gömük üçüncü molar dişlerin anormal pozisyonlarından, \% 8'inin ise patolojik nedenlerden dolayı gömülü kaldığını bildirmişlerdir.6 Bunun aksine Cassetta ve ark.16 gömük ikinci molar diş vakalarında gelişen üçüncü molarların olduğunu ve bu dişlerin varlığının ikinci molarların gömülü kalması ile ilgili olmadığını bildirmişlerdir. ${ }^{16}$ Çalışmamızda da 16 hastada görülen 21 gömük ikinci molar dişin 16'sında komşu üçüncü molar diş bulunmaktaydı ve bunların 13'ü gömük, geri kalan 3' ü anormal pozisyondaydı. Çalışmamızın sonuçlarına göre gömülü ikinci molar diş bölgelerinde patolojik oluşumun görülmemesi komşu üçüncü molarların anormal pozisyonlarının bu dişlerin gömülü kalmasına zemin hazırladığını göstermektedir. Cassetta ve ark.'nın ${ }^{16}$ sonuçlarının çalışmamızın sonuçlarıyla çelişmesinin nedeni olarak çalışmanın genç ortodontik hasta popülasyonu üzerinde yapılmasına bağlı olabileceğini, üçüncü molar dişlerin bu çalışmada henüz yeni gelişmekte olmasının etkili olabileceğini düşünmekteyiz.

Gömülü 2. molarlar genellikle mandibulada ve unilateral olarak görülmektedir. ${ }^{8,19,20}$ Cinsiyet açısından birçok çalışmada ${ }^{8,11,16,17,20,21}$ büyük farklılık olmamakla beraber erkeklerde daha sık göründüğü bildirilse de kadınlarda daha fazla olduğunu belirten çalışmalar ${ }^{5,10,22}$ da mevcuttur. Bizim çalışmamızda da literatürle uyumlu olacak şekilde gömük ikinci molarların \% 38'i maksillada \% 62 si mandibulada tespit edilmiş ve vakaların \% 87.5 'i tek taraflı olarak bulunmuştur. Cinsiyet açısından ise kadın:erkek oranı 1:1.2 olarak erkekler lehine olsa da bariz bir üstünlük göze çarpmamıştır.

Gömük ikinci molarların pozisyonları ile ilgili yapılan çalışmalarda farklı sonuçlar elde edilmiş olup genellikle mezial ve vertikal pozisyonların daha sık görüldüğü tespit edilmiştir. 10,16,17,20 Türk popülasyonu üzerinde yapılan çalışmalarda ise Şimşek Kaya ve ark. ${ }^{6}$ gömük 2. molarların en fazla MA ve derin oklüzal pozisyonda (Class C) görüldüğünü belirtirken, Bereket ve ark. ${ }^{11}$ ise 168 ikinci moları içeren 200 daimi molar üzerine gerçekleştirdikleri çalışmada vertikal pozisyonun (\%62.5) daha sık görüldüğünü bildirmişlerdir. Bizim çalışmamızda ise gömülü ikinci molarların çoğu vertikal pozisyonlu bulunmuş ve sonuçlar Bereket ve ark. ${ }^{11}$ ile Valmaseda-Castellon ve ark. ${ }^{20}$ 'In sonuçlarıyla uyum göstermiştir. Derinlik açısından ise Class $B$ ve $C$ eşit sayıda ve en yüksek görülme yüzdesini oluştururken sonuçlar Şimşek Kaya ve ark..$^{6}$ 'In çalışmasıyla uyumlu bulunmuştur.

Gömük ikinci molar dişler genellikle PR' lerde tesadüfen teşhis edilirken böylesine nadir anomalilerin 
değerlendirilmesinde KIBT' den de faydalanılabilmektedir. ${ }^{11,12,18}$ Çalışmamızda bütün dişlerin teşhisi ve değerlendirmesi PR'ler üzerinden yapılmış olup KIBT üzerinden değerlendirme yapılamaması bu çalışmanın limitasyonu olarak değerlendirilebilir.

Gömük ikinci molarların tedavisine yönelik farklı tedavi yöntemleri ileri sürülmekle birlikte uygulanacak olan tedavi yöntemi dişin gömük kalma derecesi, istenilen hareketin tipi, yaş gibi faktörlere bağlıdır. ${ }^{3,8}$ Ortodontik buton uygulamaları ile dişin sürdürülmeye çalışılması ve cerrahi olarak dişin çekimi, çekimi takiben o bölgeye 3. molar dişin doğal veya cerrahi repozisyonu uygulanabilecek tedavi yöntemleri arasındadır. ${ }^{6,11,17,19}$ Cerrahi olarak yapılan tedavilerde gömük ikinci moların veya varsa gömük üçüncü moların çekilmesi seçenekleri inferior alveolar sinir yaralanması, mandibular kanal hasarı ve lingual duvar hasarına bağlı diş kökünün submandibular loja kaçması gibi kabul edilemez tedavi sonuçlarını doğurabileceğinden dolayı bu dişlerde patolojik bir durum söz konusu olmadığı taktirde radyografik olarak, periyodik aralıklarla takip edilmeleri önerilmektedir., 6,11,23 Ortodontik tedavi prosedürleri için ideal yaş aralığı ikinci molarların kök gelişiminin tamamen sonlanmadığı 10-17 yaş arası olarak belirtilmiştir. ${ }^{11,24}$ Çalışmamızdaki hastaların yaş ortalamasının 22.68 olması ve gömülü dişlerin genellikle asemptomatik olması nedeniyle büyük çoğunluğu takip edilmişken sadece 2 hasta da cerrahi çekim ve 3. molar dişin spontan repozisyonu uygulanmıştır. Bir hastada ise ortodontik tedavi ile diş sürdürülmeye çalışılmıştır.

\section{SONUÇ}

Gömülü ikinci molarlar nadir görülen dişlerdir ve genellikle alt çenede ve tek taraflı olarak bulunurlar. PR'lerde tesadüfen fark edilen bu dişler çoğunlukla anormal pozisyonlu ve/veya gömülü üçüncü molar diş ile beraber görülürler. Tedavilerinde cerrahi ve/veya ortodontik tedavinin uygulanabildiği bu dişler asemptomatik olduğunda çoğunlukla takip edilmektedirler. Diş hekimlerinin gömülü ikinci molarların tespiti, üçüncü molar dişle ilişkisi ve bu dişler kaynaklı olası patolojilerin önlenebilmesi amacıyla özellikle PR'leri detaylı ve dikkatli bir şekilde incelemeleri ve hastaları takip etmesi önemlidir. 


\section{KAYNAKLAR}

1. Raghoebar GM, Boering G, Vissink A, Stegenga B. Eruption disturbances of permanent molars: a review. J Oral Pathol Med 1991;20:159-66.

2. Padhye MN, Dabir AV, Girotra CS, Pandhi VH. Pattern of mandibular third molar impaction in the Indian population: a retrospective clinico-radiographic survey. Oral surgery, oral medicine, oral pathology and oral radiology 2013;116:e161-6.

3. Sawicka M, Racka-Pilszak B, Rosnowska-Mazurkiewicz A. Uprighting Partially Impacted Permanent Second Molars. Angle Orthodontist 2007;77:148-54.

4. Grover PS, Lorton L. The Incidence of Unerupted Permanent Teeth and Related Clinical Cases. Oral Surg Oral Med Oral Pathol 1985;59:420-5.

5. Fu PS, Wang JC, Wu YM, Huang TK, ChenWC, Tseng YC, Tseng $\mathrm{CH}$, Hung CC. Impacted Mandibular Second Molars. Angle Orthod 2012;82:670-5.

6. Şimşek Kaya G, Yapıcı Yavuz G, Ömezli MM, Dayı E. Gömük ikinci molarlar. Atatürk Üni Diş Hek Fak Derg 2011;21:22-7.

7. McAboy CP, Grumet JT, Siegel EB, lacopino AM. Surgical uprighting and repositioning of severely impacted mandibular second molars. J Am Dent Assoc 2003;134:1459-62.

8. Palma C, Coelho A, González Y, Cahuana A. Failure of eruption of first and second permanent molars. J Clin Pediatr Dent 2003;27:239-45.

9. Baccetti T. Tooth anomalies associated with failure of eruption of first and second permanent molars. Am J Orthod Dentofacial Orthop 2000;118:608-10.

10.Srinivasan MR, Poorni S, Venkatesh A, Vasanthi B. Prevalence of impacted permanent mandibular second molars in South Indian population: A cross-sectional study.Indian J Dent Res 2016;27:540-3.

11.Bereket C, Cakir-Özkan N, Sener I, Kara I, Aktan AM, Arici N. Retrospective analysis of impacted first and second permanent molars in the Turkish population: A multicenter study. Med Oral Patol Oral Cir Bucal 2011;16:e874-8.

12.Basaran M, Bozdemir E. Gömülü Üçüncü Molar ve Kanin Dișlerin Konik Ișınlı Bilgisayarlı Tomografi ile Degerlendirilmesi. European Journal of Research in Dentistry 2018;2:47-52.

13. Magnusson $C$, Kjellberg $H$. Impaction and retention of second molars: diagnosis, treatment and outcome. A retrospective follow-up study. Angle Orthod. 2009;79:422-7.

14.Pell GJ. Impacted mandibular third molars: classification and modified techniques for removal. Dent Digest. 1933;39:330-8.

15.Shiller WR. Positional changes in mesio-angular impacted mandibular third molars during a year. J Am Dent Assoc 1979;99:460-4.

16. Cassetta M, Altieri F, Di Mambro A, Galluccio G, Barbato E. Impaction of permanent mandibular second molar: A retrospective study. Med Oral Patol Oral Cir Bucal 2013;18:e564-8.
17. Ia Monaca G, Cristalli MP, Pranno N, Galluccio G, Annibali S, Pippi R. First and second permanent molars with failed or delayed eruption: Clinical and statistical analyses. Am J Orthod Dentofacial Orthop 2019;156:355-64.

18.Evirgen Ş, Türkmenoğlu A, Yüksel HT. Uşak Üniversitesi Diş Hekimliği Fakültesine Başvuran Hastalarda "Kissing Molars" Sıklığının Araştırılması. Türkiye Klinikleri $J$ Dental Sci 2020;26:16-20.

19.Padwa BL, Dang RR, Resnick CM. Surgical Uprighting Is a Successful Procedure for Management of Impacted Mandibular Second Molars. J Oral Maxillofac Surg 2017;75:1581-90.

20.Valmaseda-Castellon E, de-la-Rosa-Gay C, GayEscoda C. Eruption disturbances of the first and second permanent molars: results of treatment in 43 cases. Am J Orthod Dentofacial Orthop 1999; 116:651-8.

21. Kenrad J, Vedtofte H, Andreasen JO, Kvetny MJ, Kjær I. A retrospective overview of treatment choice and outcome in 126 cases with arrested eruption of mandibular second molars. Clin Oral Investig 2011;15:81-7.

22. Cho SY, Ki Y, Chu V, Chan J. Impaction of permanent mandibu $\neg$ lar second molars in ethnic Chinese schoolchildren. J Can Dent As $\neg$ soc 2008;74:521-521e.

23. Mariano RC, Mariano Lde C, de Melo WM. Deep impacted mandibular second molar: a case report. Quintessence Int 2006;37:773-6.

24. Moro N, Murakami T, Tanaka T, Ohto C. Uprighting of impacted lower third molars using brass ligature wire. Aust Orthod J 2002;18:35-8.

Yazışma Adresi:

M. Fatih ŞENTÜRK

Ankara Yıldırım Beyazıt Üniversitesi

Diş Hekimliği Fakültesi

Ağız, Diş ve Çene Cerrahisi AD.

Ankara, Türkiye

Tel : +905309513687

E Posta: fatih.senturk84@gmail.com 